\title{
Synthesis of Chalcones Substituted with Nitro and Hydroxyl Group in Alkaline Medium
}

\author{
Lina Fauzi'ah ${ }^{\text {a }}$, Tutik Dwi Wahyuningsih ${ }^{b}$ \\ ${ }^{a}$ Departemen Pendidikan Kimia, FMIPA, Universitas Islam Indonesia \\ J1. Kaliurang Km 14,5 Yogyakarta 55584 \\ E-mail: lina.fauziah@uii.ac.id \\ ${ }^{\mathrm{b}}$ Departemen Kimia, FMIPA, Universitas Gadjah Mada \\ Sekip Utara, Yogyakarta, 55281
}

\begin{abstract}
ABSTRAK
Telah dilakukan sintesis turunan senyawa kalkon tersubstitusi gugus nitro dan hidroksi melalui reaksi kondensasi Claisen Schmidt. Tujuan penelitian ini adalah untuk mensintesis senyawa kalkon yang tersubstitusi gugus hirdoksi dan nitro dalam medium basa, dan mempelajari pengaruh gugus tersebut dalam reaksi kondendasi. Kalkon 1 disintesis dari 4-nitroasetofenon dan vanilin menggunakan katalis $\mathrm{NaOH} 60 \%$ (b/v dalam akuades) melalui pengadukan selama 24 jam. Kalkon 2 didapatkan dari reaksi antara 4-nitroasetofenon dan veratraldehida dengan katalis $\mathrm{NaOH} 15 \%$ selama 4 jam, sedangkan kalkon 3 disintesis dari 4-nitroasetofenon dan 6-nitroveratraldehida dalam 5\% NaOH 10 tetes. Produk hasil sintesis dikarakterisasi dengan FTIR, GC-MS dan ${ }^{1} \mathrm{H}-\mathrm{NMR}$.

Hasil penelitian menunjukkan bahwa senyawa kalkon telah berhasil disintesis dengan rendemen berturut-turut sebesar 16,$80 ; 75,83$; dan $44,11 \%$ dalam medium basa. Dari penelitian ini, dapat disimpulkan bahwa adanya gugus hidroksi dari sumber aldehida aromatik pada kalkon $\mathbf{1}$ menghambat terjadinya reaksi, sedangkan gugus nitro yang terikat pada aldehida aromatik menjadi kendala pada reaksi kalkon $\mathbf{3}$ karena sifatnya yang sensitif terhadap cahaya.
\end{abstract}

Kata Kunci : kalkon, kondensasi Claisen Schmidt, 4-nitroasetofenon, 6-nitroveratraldehida

\begin{abstract}
Synthesis of chalcone derivatives substituted with hydroxyl and nitro groups have been carried out by Claisen Schmidt condensation. Chalcone 1 was synthesized from 4-nitroacetophenone and vanillin using $\mathrm{NaOH} 60 \%$ (w/v in aquadest) as a catalyst under stirring at room temperature for $24 \mathrm{~h}$. Chalcone 2 was produced by adding $\mathrm{NaOH} 15 \%$ (w/v in ethanol) to the mixture of 4nitroacetophenone and veratraldehyde under stirring for $4 \mathrm{~h}$ whereas chalcone $\mathbf{3}$ was synthesized from 4-nitroacetophenone and 6-nitroveratraldehyde as raw materials under stirring for $6 \mathrm{~h}$ using $\mathrm{NaOH} 5 \%$ (w/v in ethanol). All of synthesized compounds were characterized using FTIR, GC-MS, and ${ }^{1} \mathrm{H}-$ NMR.

The result showed that chalcones have been successfully synthesized in $16.80 ; 75.83$; and $44.11 \%$ yield, respectively in alkaline medium. From this research, it can be concluded that the presence of hydroxyl group on the aromatic aldehyde of chalcone $\mathbf{1}$ inhibit the reaction, while the nitro group attached to the aromatic aldehyde became an obstacle on the chalcone $\mathbf{3}$ reaction because it is sensitive to light.
\end{abstract}

Key Words: chalcone, Claisen Schmidt condensation, 4-nitroacetophenone, 6-nitroveratraldehyde

Synthesis of Chalcones Substituted with Nitro and Hydroxyl Group in Alkaline Medium (Lina Fauzi'ah, Tutik Dwi Wahyuningsih) 


\section{Pendahuluan}

Senyawa kalkon atau 1,3-difenil-2Epropen-1-on memiliki kerangka benzilidinasetofenon, yaitu dua cincin benzena yang dihubungkan oleh tiga atom karbon $\alpha-\beta$ tak jenuh. Senyawa kalkon adalah intermediet rantai terbuka dalam sintesis auron yang ditemukan dalam bahan alam dalam bentuk terkonjugasi (Mahapatra dan Bharti, 2016). Gugus enon merupakan gugus yang berperan pada aktivitas biologis senyawa kalkon, hilangnya gugus enon menyebabkan senyawa kalkon menjadi tidak aktif (Singh et al., 2014). Turunan senyawa kalkon telah dilaporkan memiliki aktivitas biologis yang luas, yaitu sebagai agen kardiovaskular (Mahapatra dan Bharti, 2016), antikanker (Wan, et al., 2014; Lawrence, et al., 2006), inhibitor MAO-B (Hammuda, et al., 2016), insect antifeedant (Janaki, et al., 2012), antimalaria dan antituberkulosis (Hans, et al., 2009), serta anti-infeksi dan anti-inflammatori (Nowakowska, 2007).

Sintesis senyawa kalkon yang paling umum dilakukan melalui kondensasi Claisen Schmidt antara keton dan aldehida aromatik dalam medium asam maupun basa. Medium basa dapat digunakan pada hampir semua reaksi sintesis kalkon. Bagaimanapun, medium asam dibutuhkan untuk mensistesis senyawa kalkon yang tersubstitusi gugus $-\mathrm{OH}$ dan $-\mathrm{NO}_{2}$. Arty dan Rohmawati (2014) telah melakukan studi tentang sintesis senyawa kalkon dari bahan dasar vanilin dan $p$ nitroasetofenon menggunakan katalis asam dalam sistem gas nitrogen. Waktu optimal reaksi adalah 5 jam dengan rendemen 16,16\%. Sintesis 2'-hidroksi-3,4-dimetoksikalkon telah dilakukan oleh Susanti dan Redjeki (2011) dengan katalis $\mathrm{NaOH} 50 \%$ dan didapatkan produk padatan berwarna oranye dengan rendemen $75 \%$. Pada penelitian ini, dilakukan sintesis kalkon menggunakan katalis basa sebagai alternatif katalis yang digunakan karena karakteristik 6-nitroveratraldehida yang rentan terhadap suasana asam.

\section{Tujuan Penelitian}

Tujuan dari penelitian ini adalah:

1. Melakukan sintesis senyawa 1-(4'nitrofenil)-3-(4'-hidroksi-3'-metoksifenil)-2propen-1-on, 1-(4'-nitrofenil)-3-(3',4'dimetoksifenil)-2-propen-1-on, 1-(4'nitrofenil)-3-(4'-hidroksi-3'-metoksi-6'nitrofenil)-2-propen-1-on dalam medium basa.

2. Mempelajari pengaruh penggantian gugus hidroksi dengan metoksi pada vanilin terhadap reaksi sintesis kalkon. 
3. Mempelajari pengaruh penambahan gugus nitro pada veratraldehida terhadap reaksi sintesis kalkon.

\section{Metode Penelitian}

\section{Alat dan Bahan}

Penelitian dilakukan di laboratorium organik, Kimia, Universitas Gadjah Mada. Bahan yang digunakan dalam penelitian ini memiliki kualitas pro analisis dari Merck yang meliputi: vanilin, veratraldehida, natrium hidroksida, asam sulfat $98 \%$, asam nitrat $65 \%$, etanol, metanol, n-heksana, diklorometana (DCM) dan 4-nitroasetofenon. Peralatan yang digunakan dalam penelitian ini yaitu alat-alat gelas laboratorium, labu alas bulat, alat timbang elektrik (Libror EB-330 Shimadzu), hot plate, pengaduk magnetik, dan penentu titik lebur (electrothermal 9100). Reaksi sintesis kalkon ditunjukkan oleh Gambar 1.<smiles>CC(=O)c1ccc([N+](=O)[O-])cc1</smiles><smiles>O=Cc1ccc(O)cc1</smiles>

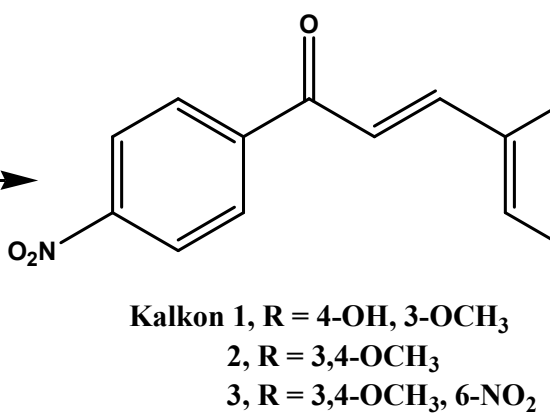

Gambar 1 Reaksi Sintesis Kalkon

Sintesis 1-(4'-nitrofenil)-3-(4'-hidroksi-3'metoksifenil)-2-propen-1-on (kalkon 1)

Sebanyak 0,76 g $(5 \mathrm{mmol})$ vanilin dilarutkan ke dalam $5 \mathrm{~mL}$ metanol. Sebanyak 0,83 g (5 mmol) 4-nitroasetofenon dilarutkan ke dalam $20 \mathrm{~mL}$ metanol dalam labu alas bulat yang terpisah. Sebanyak $2 \mathrm{~mL} \mathrm{NaOH} 60 \%$ (b/v dalam akuades) dimasukkan ke dalam labu yang berisi 4-nitroasetofenon secara bertetes-tetes. Campuran ini kemudian dimasukkan ke dalam labu yang berisi vanilin dalam metanol secara bertetes-tetes sambil dilakukan pengadukan. Kemudian dilanjutkan pengadukan selama 24 jam. Campuran reaksi dituang ke dalam air es akuades dan diasamkan dengan $\mathrm{HCl} 5 \%$ sampai $\mathrm{pH} 3$. Padatan kemudian disaring dengan penyaring Buchner, dicuci dengan akuades dingin dan dikeringkan di dalam desikator.

Padatan berwarna merah bata. Rendemen 16,80\%. FTIR ( $\left.\mathrm{cm}^{-1}, \mathrm{KBr}\right): 3379$ ($\mathrm{OH}), 1658(\mathrm{C}=\mathrm{O}), 979$ (=C-H), 1519, 1342 $(\mathrm{N}=\mathrm{O}), 1126,1033$ (C-O eter). ${ }^{1} \mathrm{H}-\mathrm{NMR}(500$ $\left.\mathrm{MHz}, \mathrm{CDCl}_{3}\right) \delta(\mathrm{ppm}): 3,87\left(\mathrm{~s}, 3 \mathrm{H}, \mathrm{OCH}_{3}\right)$, 
6,59 (dd, 1H, $J=8,40,1,95 \mathrm{~Hz}$, Ar-H), 6,85

(d,1H, $J=8,40$, Ar-H), 7,32 (d,1H, $J=1,95$ $\mathrm{Hz}, \mathrm{Ar}-\mathrm{H}), 7,57\left(\mathrm{~d}, 1 \mathrm{H}, J=15 \mathrm{~Hz}, \mathrm{C}_{\mathrm{sp} 2}-\mathrm{H}\right)$, $8,22$ (d, 2H, $J=8,45 \mathrm{~Hz}, \mathrm{Ar}-\mathrm{H}), 8,33$ (d, 2H, $J$ $=1,9 \mathrm{~Hz}, \mathrm{Ar}-\mathrm{H}), 8,38\left(\mathrm{~d}, 1 \mathrm{H}, J=15 \mathrm{~Hz}, \mathrm{C}_{\mathrm{sp} 2^{-}}\right.$ H), 9,83 (s, $1 \mathrm{H}, \mathrm{OH})$. GC-MS (kemurnian 43,67\%). MS intensitas relatif (m/z) $299\left(\mathrm{M}^{+}\right.$, base peak), 282, 252, 177, 105.

Sintesis 1-(4'-nitrofenil)-3-(3',4'-

\section{dimetoksifenil)-2-propen-1-on (kalkon 2)}

Sebanyak $0,83 \quad \mathrm{~g} \quad\left(\begin{array}{ll}5 & \mathrm{mmol}\end{array}\right)$

veratraldehida dan $0,83 \mathrm{~g} \quad(5 \mathrm{mmol})$ 4nitroasetofenon dilarutkan dengan $25 \mathrm{~mL}$ etanol. Selanjutnya sebanyak $10 \mathrm{~mL} \mathrm{NaOH}$ $15 \%$ (b/v dalam etanol) dimasukkan ke dalamnya secara bertetes-tetes. Campuran reaksi diaduk selama 4 jam pada temperatur kamar dan disimpan di dalam lemari pendingin selama semalam. Padatan yang terbentuk disaring dengan penyaring Buchner, dicuci dengan akuades dingin, dan dikeringkan di dalam desikator.

Padatan berwarna kuning. Rendemen 75,83\%. M.p. : $173-179^{\circ} \mathrm{C}$. FTIR $\left(\mathrm{cm}^{-1}, \mathrm{KBr}\right)$ : 3070 (Ar-H), $2924\left(\mathrm{C}_{\mathrm{sp} 3}-\mathrm{H}\right), 1658(\mathrm{C}=\mathrm{O})$, $1581(\mathrm{C}=\mathrm{C}$ Ar), $1519(-\mathrm{N}=\mathrm{O}), 1273,1033$ (-C$\mathrm{O}$ eter), $987\left(\mathrm{C}_{\mathrm{sp} 2}-\mathrm{H}\right) .{ }^{1} \mathrm{H}-\mathrm{NMR}(500 \mathrm{MHz}$, $\left.\mathrm{CDCl}_{3}\right) \delta: 3,93\left(\mathrm{~s}, 3 \mathrm{H}, \mathrm{OCH}_{3}\right), 3,95(\mathrm{~s}, 3 \mathrm{H}$, $\left.\mathrm{OCH}_{3}\right), 6,91$ (d, 1H, $\left.J=8,40 \mathrm{~Hz}, \mathrm{Ar}-\mathrm{H}\right), 7,15$ (d, 1H, $J=1,90 \mathrm{~Hz}$, Ar-H), 7,26 (dd, 1H, $J=$ $8,40 ; 1,90 \mathrm{~Hz}, \mathrm{Ar}-\mathrm{H}), 7,33$ (d, 1H, $J=15,60$
$\left.\mathrm{Hz}, \mathrm{C}_{\mathrm{sp} 2}-\mathrm{H}\right), 7,78\left(\mathrm{~d}, 1 \mathrm{H}, J=15,60 \mathrm{~Hz}, \mathrm{C}_{\mathrm{sp} 2^{-}}\right.$ H), 8,12 (d, 2H, $J=9,1 \mathrm{~Hz}, \operatorname{Ar}-\mathrm{H}), 8,34$ (d, $2 \mathrm{H}, J=1,95 \mathrm{~Hz}, \mathrm{Ar}-\mathrm{H})$. GC-MS (kemurnian 92.60\%). MS intensitas relatif $(\mathrm{m} / \mathrm{z}): 313$ ( $\mathrm{M}^{+}$, base peak), 298,252, 191, 163.

\section{Sintesis 1-(4'-nitrofenil)-3-(4'-hidroksi-3'-} metoksi-6'-nitrofenil)-2-propen-1-on

\section{(kalkon 3)}

6-nitroasetofenon sebagai bahan dasar dari kalkon 3 didapatkan dari hasil nitrasi veratraldehida menggunakan $\mathrm{HNO}_{3}$ dan $\mathrm{H}_{2} \mathrm{SO}_{4}$. Sebanyak 1,06 g (5 mmol) 6nitroveratraldehida dan $0,83 \mathrm{~g}(5 \mathrm{mmol})$ 4nitroasetofenon dilarutkan menggunakan 30 $\mathrm{mL}$ etanol. Selanjutnya sebanyak 10 tetes $\mathrm{NaOH} 5 \%$ (b/v dalam etanol) ditambahkan ke dalamnya tetes demi tetes. Campuran reaksi diaduk selama 6 jam pada temperatur kamar dan disimpan di dalam lemari pendingin selama semalam. Padatan yang terbentuk disaring dengan penyaring Buchner, dicuci dengan akuades dingin, dan dikeringkan di dalam desikator.

Padatan berwarna kuning kehijauan. Rendemen 44,11\%. M.p.: 203-206 ${ }^{\circ} \mathrm{C}$. FTIR $\left(\mathrm{cm}^{-1}, \mathrm{KBr}\right)$ : $3109\left(\mathrm{C}_{\mathrm{sp} 2}-\mathrm{H}\right), 1658(\mathrm{C}=\mathrm{O})$, $1597(\mathrm{C}=\mathrm{C}), 1566(\mathrm{C}=\mathrm{C}$ Ar), $1519(-\mathrm{N}=\mathrm{O})$, 1280, 1064 (C-O eter), $987\left(\mathrm{C}_{\mathrm{sp} 2-\mathrm{H}) .}{ }^{1} \mathrm{H}-\mathrm{NMR}\right.$ $\left(500 \mathrm{MHz}, \mathrm{CDCl}_{3}\right) \delta$ (ppm): 4,01 (s, $3 \mathrm{H}$, $\left.\mathrm{OCH}_{3}\right), 4,04\left(\mathrm{~s}, 3 \mathrm{H}, \mathrm{OCH}_{3}\right), 7,04(\mathrm{~s}, 1 \mathrm{H}, \mathrm{Ar}-$ $\mathrm{H}), 7,11\left(\mathrm{~d}, 1 \mathrm{H}, J=15,55 \mathrm{~Hz}, \mathrm{C}_{\mathrm{sp} 2}-\mathrm{H}\right), 7,69$ (s, 
1H, Ar-H), 8,14 (d, 2H, $J=9 \mathrm{~Hz}, \mathrm{Ar}-\mathrm{H}), 8,22$ (d, $\left.1 \mathrm{H}, J=15,60 \mathrm{~Hz}, \mathrm{C}_{\mathrm{sp} 2}-\mathrm{H}\right), 8,37$ (d, 2H, $J=$ 8,45 Hz, Ar-H). GC-MS (kemurnian 67,67\%). MS intensitas relatif $(\mathrm{m} / \mathrm{z}): 358\left[\mathrm{M}^{+}\right], 312$ (base peak), 282, 164, 150, 104.

\section{Karakterisasi Produk Hasil Sintesis}

Spektra FTIR didapatkan dari hasil analisis produk berupa padatan dalam pelet $\mathrm{KBr}$ dengan spectrofotometer fourier transform infra red (FTIR, Shimadzu Prestige 21), Kromatogram dan spektra massa merupakan hasil analisis dengan kromatografi gas-spektroskopi massa (GC-MS, ShimadzuQP 2101S), sedangkan spektra ${ }^{1} \mathrm{H}-\mathrm{NMR}$ adalah hasil analisis spektrometer resonansi magnetik inti proton dan karbon (NMR, JEOL, JNMECA ${ }^{1} \mathrm{H}(500 \mathrm{MHz})$ dengan standar internal TMS.

\section{Pembahasan}

Senyawa kalkon 1, 2, dan 3 telah berhasil disintesis dengan pengadukan reaktan dan $\mathrm{NaOH}$ sebagai katalis pada temperatur kamar. Produk yang dihasilkan berupa padatan dengan warna yang berbeda, ditunjukkan oleh Gambar 2. Terbentuknya produk dibuktikan dengan spektra FTIR, kromatogram dan spektra massa GC-MS, serta spektra ${ }^{1} \mathrm{H}-\mathrm{NMR}$.

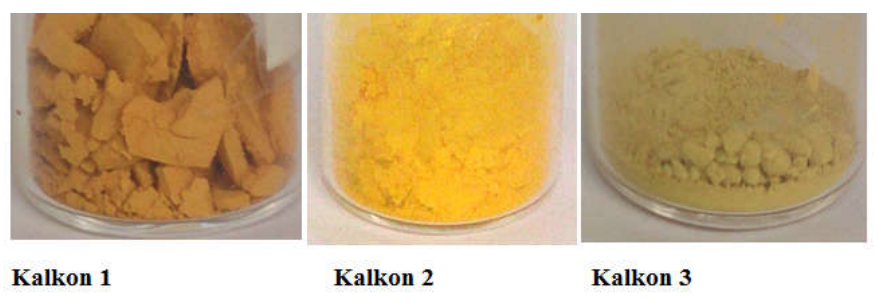

Gambar 2 Produk Hasil Sintesis Kalkon

\section{Spektra FTIR}

Spektra FTIR dapat memberikan gambaran umum terbentuknya produk senyawa kalkon. Pergeseran spektra FTIR pada daerah gugus fungsi merupakan indikasi perubahan gugus fungsi. Pada Gambar 3, disajikan perbandingan spektra FTIR dari kalkon 1, 2 dan 3. 


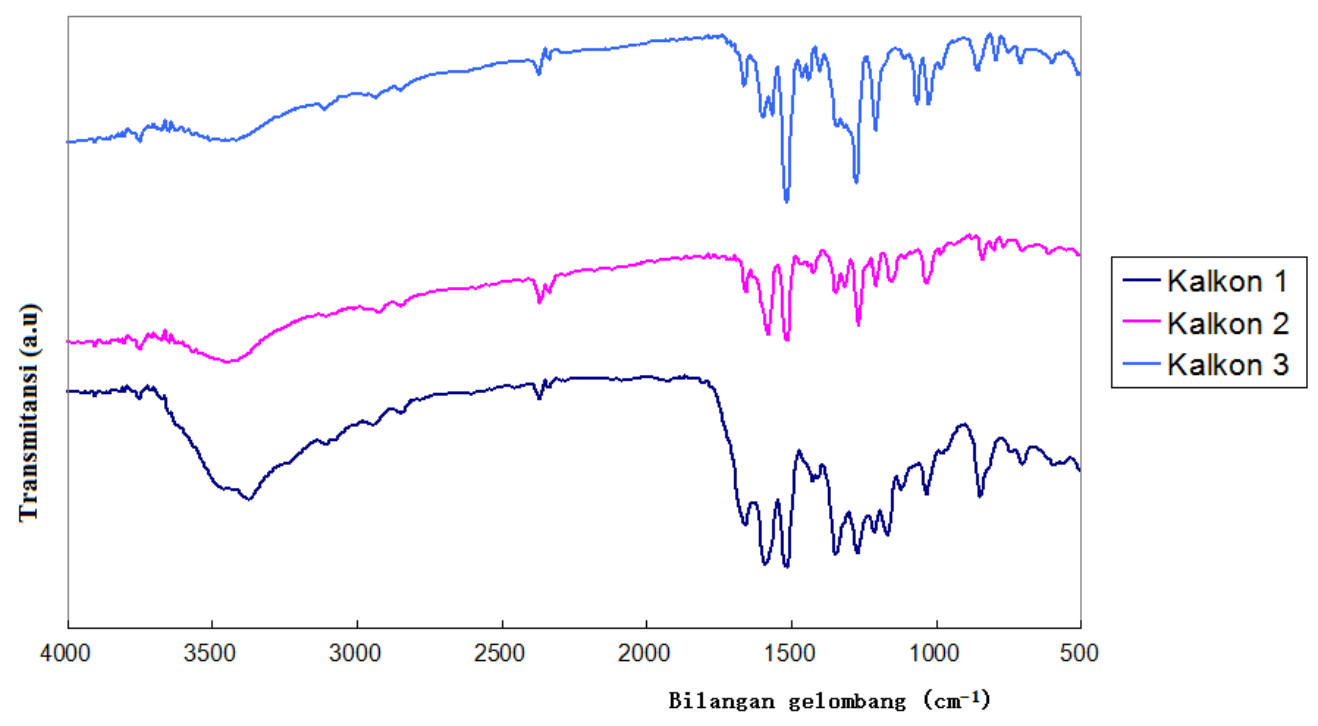

Gambar 3 Perbandingan Spektra FTIR

Identifikasi gugus karbonil $(\mathrm{C}=\mathrm{O})$ pada kalkon merupakan hal yang sangat penting karena terbentuknya produk kalkon dapat dilihat dari pergeseran spektra FTIR. Serapan tajam pada bilangan gelombang 1630-1660 $\mathrm{cm}^{-1}$ mengindikasikan adanya gugus $\mathrm{C}=\mathrm{O}$ pada kalkon (Choudhary dan Juyal, 2011). Besarnya panjang gelombang yang ditunjukkan oleh masing-masing gugus karbonil dipengaruhi oleh beberapa faktor, yaitu resonansi, ikatan hidrogen intra dan atau intermolekular, tipe substituen yang terikat pada cincin fenil, serta pengaruh vibrasi regangan dari gugus karbonil $(\mathrm{C}=\mathrm{O}) \quad \alpha-\beta$ takjenuh (Jagadeesh et al., 2015).

Serapan dari $\mathrm{C}-\mathrm{H}$ alkena merupakan indikasi awal struktur geometri kalkon yang terbentuk. Adanya gugus enon memungkinkan produk yang terbentuk memiliki isomer cis dan trans. Berdasarkan penelitian yang dilakukan oleh Vanangamudi et al. (2011), serapan $\mathrm{C}=\mathrm{O}$ dari kalkon dengan isomer cis teramati pada bilangan gelombang 1627-1699 $\mathrm{cm}^{-1}$, sedangkan serapan $\mathrm{C}=\mathrm{O}$ isomer trans pada $1584-1637 \mathrm{~cm}^{-1}$. Isomer cis menyerap pada frekuensi vibrasi yang lebih tinggi dari pada isomer trans. Spektra FTIR ketiga produk kalkon menunjukkan bahwa produk hasil sintesis didominasi oleh isomer trans.

Vibrasi $\mathrm{C}=\mathrm{O}$ dari produk senyawa kalkon 1 dan $\mathbf{2}$ ditunjukkan oleh serapan pada bilangan gelombang $1658 \mathrm{~cm}^{-1}$ yang mengalami pergeseran dari vibrasi $\mathrm{C}=\mathrm{O}$ 4nitroasetofenon, yaitu $1689 \mathrm{~cm}^{-1}$. Sedangkan pada kalkon 3 vibrasi regangan $\mathrm{C}=\mathrm{O}$ teramati sebagai puncak tajam pada $1666 \mathrm{~cm}^{-1}$. Adanya gugus pemberi elektron $(D G)$ mengakibatkan $\mathrm{C}=\mathrm{O}$ pada gugus enon memiliki frekuensi Synthesis of Chalcones Substituted with Nitro and Hydroxyl Group in Alkaline Medium (Lina Fauzi'ah, Tutik Dwi Wahyuningsih) 
serapan yang lebih rendah sedangkan gugus penarik elektron $(E W G)$ menyebabkan peningkatan frekuensi serapan $\mathrm{C}=\mathrm{O}$ pada senyawa kalkon (Vanangamudi et al., 2011). Gugus pemberi elektron menyebabkan terjadinya delokalisasi elektron $\pi$ sehingga dapat menurunkan order ikatan $\mathrm{C}=\mathrm{O}$ dan meningkatkan order ikatan antara karbon $\mathrm{C}=\mathrm{O}$ dan karbon $\alpha$ (Jagadeesh et al., 2015). Pengaruh gugus hidroksi yang terikat pada posisi para pada kalkon 1 menyebabkan terjadinya resonansi seperti yang ditunjukkan oleh Gambar 4, sedangkan adanya gugus nitro sebagai penarik elektron yang menyebabkan serapan $\mathrm{C}=\mathrm{O}$ kalkon 3 lebih tinggi dari pada kalkon 1 dan 2.

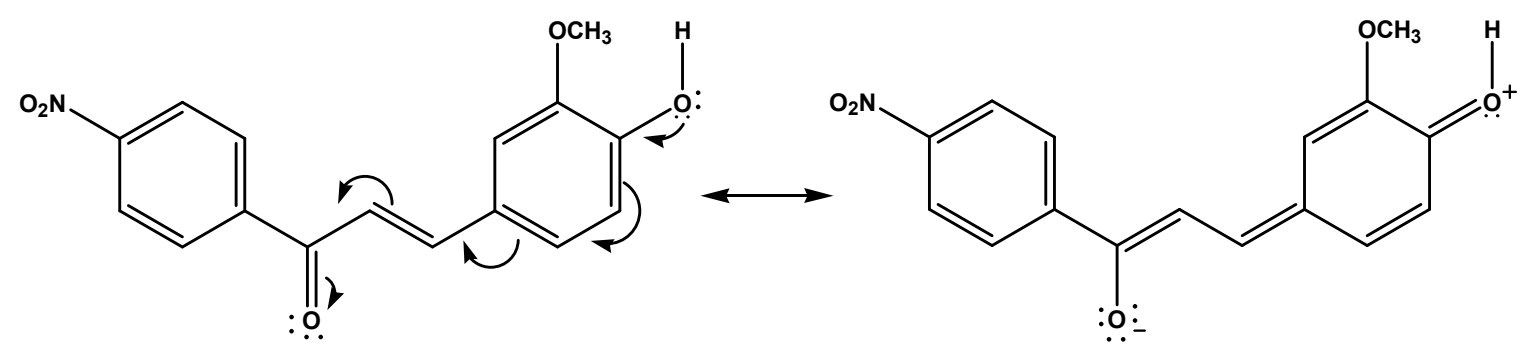

Gambar 4 Resonansi Kalkon 1

Vibrasi $\mathrm{C}=\mathrm{C}$ dihasilkan dari vibrasi $\mathrm{C}=\mathrm{C}$ aromatik dari cincin benzena dan $\mathrm{C}=\mathrm{C}$ alifatik dari gugus enon. Serapan $\mathrm{C}=\mathrm{C}$ aromatik dari kalkon 1 teramati sebagai puncak tajam pada bilangan gelombang 1589 $\mathrm{cm}^{-1}$. Penggantian gugus hidroksi dengan metoksi menurunkan serapan $\mathrm{C}=\mathrm{C}$ aromatik pada kalkon 2 menjadi $1588 \mathrm{~cm}^{-1,}$ sedangkan pada kalkon 3 teramati pada $1566 \mathrm{~cm}^{-1}$. Serapan $\mathrm{C}=\mathrm{C}$ alifatik pada kalkon $\mathbf{1}$ dan $\mathbf{2}$ mengalami overlap dengan serapan $\mathrm{C}=\mathrm{C}$ aromatik sehingga vibrasi teramati sebagai puncak yang agak melebar. Terbentuknya produk kalkon isomer trans diperkuat dengan vibrasi pada bilangan gelombang $979 \mathrm{~cm}^{-1}$ dari produk kalkon 1 yang merupakan serapan khas dari C-H alkena trans. Pada kalkon 2 dan 3, vibrasi $\mathrm{C}-\mathrm{H}$ alkena dari gugus enon teramati pada $987 \mathrm{~cm}^{-1}$.

\section{Spektra ${ }^{1}$ H-NMR}

Hasil analisis produk dengan spektrometer NMR memperkuat dugaan terbentuknya produk kalkon yang didominasi oleh isomer trans. Senyawa kalkon dengan isomer trans memiliki nilai tetapan kopling $(J)$ pada H- $\alpha$ dan $-\beta$ sebesar 15,3-15,9 Hz (Dias et al., 2013). Dari spektra ${ }^{1} \mathrm{H}-\mathrm{NMR}$ kalkon 1, didapatkan dua proton yang memiliki nilai $J=$ $15 \mathrm{~Hz}$, yaitu pada pergeseran kimia 7,57 dan 8,38 ppm. Geometri pada kalkon trans 
menyebabkan posisi H- $\alpha$ menjadi lebih terlindungi dari pada H- $\beta$. Sehingga proton dengan pergeseran kimia lebih kecil adalah H$\alpha$. Pada kalkon B, H- $\alpha$ dan $-\beta$ teramati pada masing-masing pergeseran kimia 7,33 dan 7,78 dengan nilai $J=15,60 \mathrm{~Hz}$. Pada kalkon 2, penggantian gugus hidroksi dengan metoksi mempengaruhi lingkungan kimia dari $\mathrm{H}-\alpha$ dan $-\beta$. Adanya gugus hidroksi memungkinkan terjadinya delokalisasi elektron $\pi$ membentuk struktur resonansi yang ditunjukkan oleh Gambar 4. Awan elektron tertarik ke arah atom $\mathrm{O}$ pada gugus $\mathrm{C}=\mathrm{O}$ kalkon $\mathbf{1}$ yang menyebabkan H- $\beta$ menjadi kurang terlindungi dan memiliki pergeseran kimia yang lebih tinggi jika dibandingkan H- $\beta$ pada kalkon 2.

Pada kalkon 3, H- $\alpha$ dan $-\beta$ teramati pada pergeseran kimia 7,11 dan 8,22 ppm dengan nilai $J=15,55$ dan $15,60 \mathrm{~Hz}$. Tingginya persegeran kimia dari H- $\beta$ disebabkan oleh adanya gugus nitro pada posisi orto yang memberikan efek induktif dan memungkinkan terjadinya delokalisasi elektron $\pi$.

\section{Mekanisme Reaksi}

Sintesis senyawa kalkon dengan katalis basa berlangsung melalui reaksi kondensasi Claisen Schmidt antara aldehida dan keton aromatik. Adanya gugus yang terikat pada sumber keton dan aldehida dapat mempengaruhi reaktivitas reaktan yang berdampak pada kondisi reaksi. Hal ini disebabkan oleh efek induktif, efek hiperkonjugasi, dan sifat keasaman dari reaktan.

$$
\text { Kalkon } 1 \text { berhasil disintesis }
$$
menggunakan katalis basa dengan rendemen $16,80 \%$, lebih tinggi dari sintesis yang dilakukan oleh Arty dan Rohmawati (2014) dengan katalis asam. Sifat dari 4nitroasetofenon yang kurang larut terhadap metanol merupakan kendala dari reaksi ini. Vanilin memiliki gugus hidroksi yang bersifat asam sehingga pada medium basa akan membentuk garam vanilat seperti yang ditunjukkan oleh Gambar 5. Hal ini dapat memperlambat pembentukan karbanion karena vanilin dan 4-nitroasetofenon berkompetisi untuk bereaksi dengan basa sehingga pada reaksi ini, dibutuhkan $\mathrm{NaOH}$ dengan konsentrasi tinggi, yaitu $60 \% \quad(\mathrm{~b} / \mathrm{v}$ dalam akuades). Dengan demikian, dapat dikatakan bahwa berdasarkan perbandingan rendemen, sintesis kalkon $\mathbf{1}$ yang memiliki gugus hidroksi pada sumber aldehida lebih efektif dilakukan dalam medium basa. Hal ini dapat dijelaskan dari tinjauan mekanisme reaksi.

Mekanisme sintesis kalkon dengan katalis asam melalui tahap pembentukan gugus etilen sebagai nukleofil, dan pembentukan karbokation dari sumber aldehida (vanilin). Reaksi kondensasi dihasilkan dari serangan elektron dari ikatan $\pi$ 
terhadap karbokation. Jika dibandingkan dengan sintesis kalkon dengan katalis basa yang dihasilkan dari serangan karbena pada gugus karbonil, dapat dikatakan bahwa terbentuknya produk memungkinkan lebih efektif jika dilakukan dalam suasana basa. Adanya gugus hidroksi pada vanilin menambah kerapatan elektron pada gugus karbonil sehingga memperlambat pembentukan karbokation melalui katalis asam, sedangkan gugus nitro pada sumber asetofenon mengurangi kerapatan elektron pada gugus karbonil sehingga mempermudah pembentukan karbena pada suasana basa.

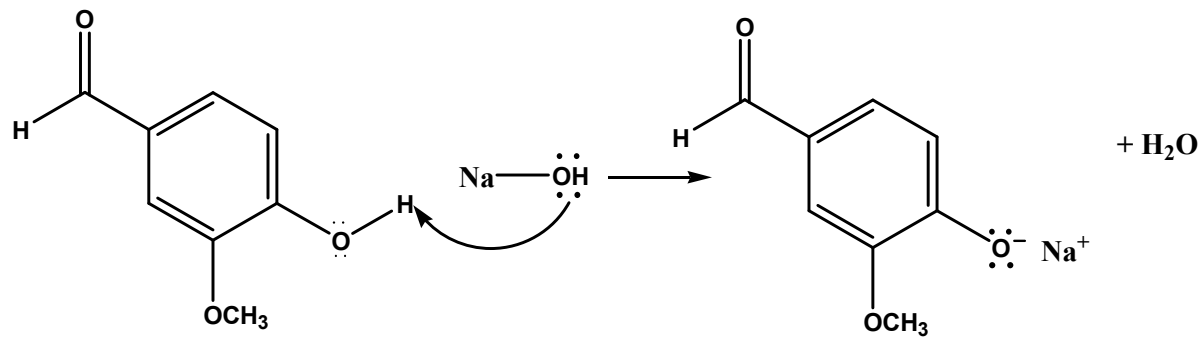

Gambar 5 Reaksi Pembentukan Garam Vanilat

Reaksi dilakukan dengan pengadukan pada temperatur kamar dan jalannya reaksi dikontrol menggunakan KLT dengan DCM sebagai eluen. Reaksi dihentikan setelah 24 jam. Tahapan working-up dilakukan dengan pengasaman campuran reaksi menggunakan $\mathrm{HCl} 5 \%$ untuk mengembalikan produk dari bentuk garam menjadi senyawa target.

Kalkon 2 berhasil disintesis melalui pengadukan pada suhu kamar selama 4 jam dengan rendemen yang paling tinggi jika dibandingkan dengan kalkon $\mathbf{1}$ dan 3, yaitu sebesar 75,83\%. Kebenaran gugus hidroksi yang dapat memperlambat reaksi kondensasi dapat teramati dengan penggantian gugus hidroksi dengan metoksi. Ketika gugus hidroksi pada vanilin diganti dengan metoksi, reaksi lebih cepat terjadi dengan rendemen yang lebih tinggi. Selain mempengaruhi waktu reaksi dan rendemen, keberadaan substituen juga mempengaruhi prosentase katalis yang dibutuhkan. Katalis yang dibutuhkan dalam reaksi ini adalah $\mathrm{NaOH} 15 \% \quad(\mathrm{~b} / \mathrm{v}$ dalam etanol), lebih encer jika dibandingkan dengan katalis dalam reaksi kalkon 1. Sintesis kalkon 2 tidak dapat dilakukan dalam $\mathrm{NaOH}$ pekat. Penggunaan $\mathrm{NaOH}$ pekat akan membuat warna produk reaksi menghitam dan ketika dilakukan analisis dengan FTIR, tidak teridentifikasi terbentuknya kalkon. Kalkon 3 berhasil disintesis dengan pengadukan pada suhu kamar selama 6 jam menggunakan 
katalis $\mathrm{NaOH} 5 \%$ (b/v dalam etanol) sebanyak 10 tetes. Penggunaan $\mathrm{NaOH}$ dengan konsentrasi lebih dari 5\% dan penambahan $\mathrm{NaOH}$ lebih dari 10 tetes menyebabkan produk reaksi menghitam. Hal ini dikarenakan kalkon 3 disintensis dari 6-nitroveratraldehida yang memiliki sifat sensitif terhadap cahaya dan panas. Mekanisme reaksi pembentukan senyawa kalkon dalam medium basa diawali dengan abstraksi (penyerangan) basa terhadap $\mathrm{H}-\alpha$ keton aromatik untuk membentuk karbanion. Karbanion kemudian menyerang atom $\mathrm{C}$ karbonil dari sumber aldehida sehingga terjadi kondensasi. Tahap selanjutnya adalah dehidrasi, yaitu pelepasan gugus $\mathrm{H}_{2} \mathrm{O}$ dilanjutkan dengan protonasi sehingga didapatkan senyawa $\alpha-\beta$ tak jenuh, yaitu kalkon.

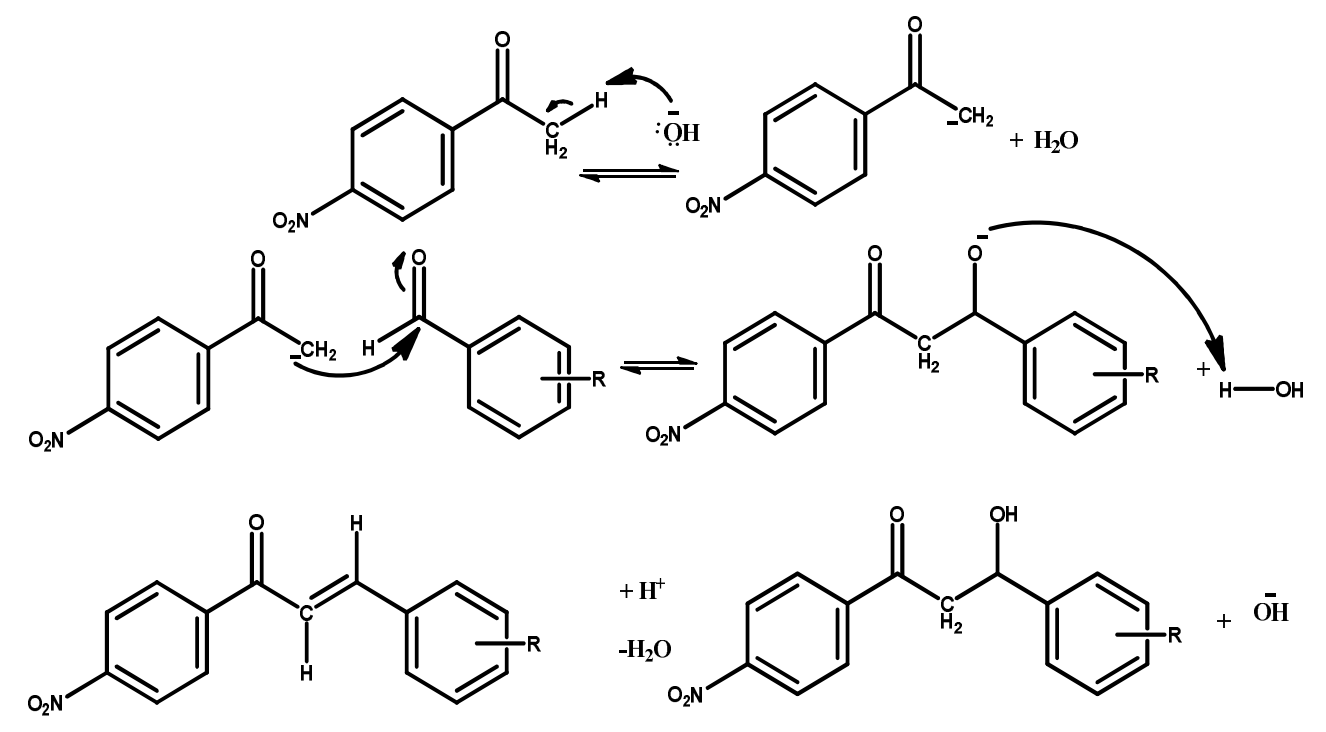

Gambar 6 Prediksi Mekanisme Reaksi Sintesis Kalkon dalam Medium Basa

Dari prediksi mekanisme reaksi, dapat dikatakan bahwa adanya gugus nitro pada kalkon 3 mengurangi kerapatan elektron pada aldehida aromatik, sehingga seharusnya dapat mempercepat terjadinya reaksi kondensasi. Tetapi karena sifat dari 6-nitroveratraldehida yang sensitif terhadap cahaya dan memiliki kemungkinan untuk berubah menjadi nitroso, rendemen kalkon $\mathbf{3}$ lebih rendah jika dibandingkan dengan kalkon 2. Sintesis kalkon 1 terhambat oleh gugus hidroksi, sifat 6-nitroveratraldehida yang sensitif terhadap cahaya menjadi kendala untuk reaksi kalkon 3, sehingga kalkon 2 memiliki rendemen yang paling tinggi. Reaksi kondensasi Claissen Schmidt dapat berlangsung dalam medium asam maupun basa. Secara teori, sintesis kalkon yang memiliki gugus hidroksi dan nitro 
pada sumber aldehida membutuhkan medium asam untuk dapat berlangsung tetapi berdasarkan hasil penelitian, sintesis kalkon $\mathbf{1}$ lebih efektif dengan katalis basa (berdasarkan jumlah rendemen), sintesis kalkon $\mathbf{3}$ yang memiliki dua gugus nitro juga dapat dilakukan dalam medium basa, dan ketiga senyawa kalkon yang memiliki gugus nitro dari sumber keton juga berhasil disintesis dalam medium basa.

\section{Kesimpulan}

Dari hasil penelitian, dapat ditarik kesimpulan sebagai berikut:

1. Turunan kalkon, yaitu 1-(4'-nitrofenil)-3(4'-hidroksi-3'-metoksifenil)-2-propen-1on, 1-(4'-nitrofenil)-3-(3',4'dimetoksifenil)-2-propen-1-on, 1-(4'nitrofenil)-3-(4'-hidroksi-3'-metoksi-6'nitrofenil)-2-propen-1-on telah berhasil disintesis dengan rendemen berturut-turut 16,$80 ; 75,83$; dan $44,11 \%$ dalam medium basa.

2. Pengaruh penggantian gugus hidroksi dengan gugus metoksi pada vanilin mempercepat terbentuknya produk, meningkatkan rendemen, dan menurunkan konsentrasi katalis $\mathrm{NaOH}$ yang diperlukan pada reaksi sintesis kalkon 2.
3. Pengaruh penambahan gugus nitro pada veratraldehida menurunkan konsentrasi katalis $\mathrm{NaOH}$ yang diperlukan pada reaksi kalkon 3 dan menurunkan rendemen karena sifat 6-nitroveratraldehida yang rentan terhadap cahaya.

\section{Pustaka}

Arty, I.S., Rohmawati, D., 2014, Optimization of Condensation Reaction Time Between Vanillin and pNitroacetophenone in Acid Catalysts, J.Sains Dasar 3(1): 34-38.

Choudhary, A.N. dan Juyal, V., 2011, Synthesis of Chalcone and Their Derivatives as Antimicrobial Agents, Int. J. Pharm. Pharm. Sci., 3-6.

Dias, T.A., Duarte, L.C., Lima, C.F. and Proenca, M.F., 2013, Superior Anticancer Activity of Halogenated Chalcones and Flavonols Over the Natural Flavonols Quercetin, Eur. J. Med. Chem., 65, 500-10.

Hammuda, A., Shalaby, R., Rovida, S., Edmondson, D.E., Binda, C., Khalil, A., 2016, Design and Synthesis of Novel Chalcones as Potent Selective Monoamine Oxidase-B Inhibitors, Eur. J. Med. Chem., doi:10.1016/j.ejmech.2016.02.038.

Hans, R.H., Guantai, E.M., Lategan, C., Smith, P.J., Wan, B., Franzblau, S.G., Gut, J., Rosethal, P.J., Chibale, K., 2009, Synthesis, Antimalarial and Antitubercular Activity of Acetylenic Chalcones, Bioorg. Med. Chem. Lett. 20: 942-944.

Jagadeesh, M., Lavanya, M., Babu, B.H., Hong, K., Ma, R., Kim, J., and Kim. T.K., 2015, Synthesis and Detailed

Synthesis of Chalcones Substituted with Nitro and Hydroxyl Group in Alkaline Medium 
Spectroscopic Characterization of Various Hydroxy-functionalized Fluorescent Chalcones: A Combined Experimental and Theoretical Study, Spectrochim Acta A Mol Biomol Spectrosc., 150: 557-564, http://dx.doi.org/10.1016/j.saa.2015.0 $\underline{5.085}$.

Janaki, P., Sekar, K.G., Thirunarayanan, G., 2012, Synthesis, Spectral Correlation and Insect Antifeedant Activities of Some 2-Benzimidazole Chalcones, $J$. Saudi Chem. Soc. 20; 58-68, http://dx.doi.org/10.1016/j.jscs.2012.1 1.013.

Lawrence, N.J., Patterson, R.P., Ooi, L.L., Cook, D., and Ducki, S., 2006, Effect of Alfa-Substitutions on Structure and Biological Activity of Anticancer Chalcones, Med. Chem. Lett. (16): 5844-48.

Mahapatra, D.K. dan Bharti, S.K., 2016, Therapeutic Potential of Chalcones as Cardiovascular Agents, Life Sci.148: 154-172, http://dx.doi.org/10.1016/j.lfs.2016.02 .048 .

Nowakowska, Z., 2007, A Review of Antiinfective and Anti-inflammatory Chalcones, Eur. J. Med. Chem. 42:
125-137, doi:10.1016/j.ejmech.2006.09.019.

Singh, P., Anand, A., and Kumar, V., 2014, Recent Developments in Biological Activities of Chalcones: A Mini Review, Eur. J. Med. Chem. 85: 758777 , http://dx.doi.org/10.1016/j.ejmech.20 14.08 .033 .

Susanti, E. dan Redjeki, T., 2011, Syntesis of 2',4'-Dihydroxy-3,4-

Dimethoxychalcone from Vanillin by Claisen-Schmidt Condensation, Prosiding Seminar Kimia dan Pendidikan Kimia UNS, 7 Mei 2011, Solo.

Wan, M., Xu, L., Hua L., Li, A., Li, S., Lu, W., Pang, Y., Cao, C., Liu, X., and Jiao, P., 2014, Synthesis and Evaluation of Novel Isoxazolyl Chalcones as Potential Anticancer Agents, Bioorg. Chem.(54): 38-43, http://dx.doi.org/10.1016/j.bioorg.201 4.03.004.

Vanangamudi, G., Subramanian, M., Jayanthi, P., Arulkumaran, R., Kamalakkannan, D. and Thirunarayanan, G., 2011, IR and NMR Spectral Studies of Some 2Hydroxy-1-Naphthyl Chalcones: Assessment of Substituent Effects, Arabian J. Chem., 1-8.

Synthesis of Chalcones Substituted with Nitro and Hydroxyl Group in Alkaline Medium 